\title{
A Prática dos Afetos (Estética em Gesualdo)
}

\author{
Luís ANTÔNIO GIRON
}

\section{Nota Intodutória}

Realizei este ensaio como tabalho para o curso "A Função Poética na Música", do Prof. Dr. Sylvio Crespo, em 1996, por sugestão do Prof. Dr. José Eduardo Martins. Mas o assunto já resultava de uma longa reflexão que eu começara a fazer em torno do nascimento da estética musical ainda na década de 80 , quando minha intenção era realizar uma dissertação sobre o tema, centrada justamente na obra de Carlo Gesualdo de Venosa (nascido em Nápoles em 1561 e morto em Avellino em 8 de setembro de 1613).

Ora, o príncipe Gesualdo é um personagem atraente sob todos os aspectos, especialmente os passionais, bastante conhecidos e acentuados por vários escritores, especialmente Aldous Huxley, num dos ensaios de Ape and Essence (O Macaco e a Essência) ${ }^{1}$. O nobre napolitano mandou assassinar a esposa e o amante em seu palazzo napolitano. $\mathrm{O}$ dado fundamental aqui é que o crime, e o castigo do remorso, ganham um espelho - talvez refratário, talvez monstruosamente deformado nos madrigais cromáticos, motetos e canzone do compositor. De uma forma bizarra, talvez, a teoria dos afetos (Affektenteorie) barroca teria ali, na maneirista escritura gesualdiana, os seus primeiros conceitos, elaborados na prática, na dor de escrever música sob a égide do fracasso

1. Aldous Huxley, Ape and Essence, New York, Everyman Classics 1948, 1950. 
amoroso. A biografia de Glenn Watkins, de 1973, acentua os traços dramáticos do caso Gesualdo².

O compositor Igor Stravinsky foi o responsável pelo revival da música do músico diletante. Adaptou para orquestra alguns de seus madrigais e tratou de analissar suas obras nas Conversações com Robert $\mathrm{Craft}^{3}$. A música de Gesualdo encontra certo eco no mundo discográfico, com gravações e novas versões, algumas até buscando barroquizá-lo, intoduzindo um basso continuo que, talvez, ele nunca tivesse querido empregar. Gesualdo voltou à ordem do dia em 1995, quando o compositor russo Alfred Schnittke apresentou a ópera Gesualdo, na qual tenta unir a trama romanesca e lançar mão do vocabulário do compositor, transfigurando-o para uma linguagem politonal. E com o filme do diretor Bernardo Bertolucci, a estrear no ano 2000, a glória por assim dizer anedótica do príncipe de Venosa está garantida.

Entretanto, o tema romântico e ofait divers terminam por ocultar, mais uma vez, a importância capital que a produção do compositor teve na história da música e, especialmente, para a instauração de um pensamento banhado em estímulos da experiência sonora e existencial que hoje denominamos "Estética". O que mais me estimulou a pensar em Gesualdo fora do ambiente passional foram dois ensaios; o de Jackson ${ }^{4}$, que analisa o cromatismo de Frescobaldi e o associa ao de Gesualdo, e do de Carl Dahlhaus ${ }^{5}$, este, sim, debruçando-se sobre as idiossincrasias harmônicas daquele que Stravinsky chamou de "precursor de Wagner"6.

O presente trabalho é, assim, paradoxal, pois se trata de um ensaio de resgate do caráter extramusical da poética gesualdiana a partir dos fundamentos de sua escritura musical. Em Gesualdo, uma filosofia existencial e a estética estão entranhadas em suas enarmonias, cromatismos,

2. Glenn Watkins, Gesualdo, the Man and his Music, Preface by Igor Stravinsky, London, Oxford University Press, 1973.

3. Igor Stravinsky e Robert Craft, Conversations. New York, 1959. Obra publicada pela editora Perspectiva como Conversações com Stravinsky, em 1992.

4. R Jackson, "On Frescobaldi's Chromaticism and its Background", Musical Quarterly, Ivii, 1971, p. 255.

5. Carl Dahlhaus, "Zur chromatischen Technik Carlo Gesualdos", Analecta Musicologica, Musikabteilung des Deutschen historischen Instituts in Rom, 1967, $\mathrm{n}^{\circ} 4$, Köln, p. 77.

6. Idem, nota 3 . 
saltos intervalares olímpicos. Debruçar-se sobre ela é como estar num mundo desusado que prenuncia o Romantismo e o niilismo contemporâneo. Mas sua música continua a viver (embora sem muitos ouvintes ou executantes) como um grifo que nos assusta, encanta e suscita a análise de sua anatomia excêntrica. Ela soa como discurso poético que, vez por outra, deriva para o argumento estético. É uma quase não-música, que inspirou os primeiros tratadistas do Barroco a elaborarem axiomas sobre como a música deveria exprimir sentimentos. A prática dos afetos levou à elaboração de sua teoria.

\section{Defesa da Neutralidade}

Antes de qualquer apresentação, convém começar por um fragmento de três compassos, tentando subtrair qualquer referência histórica e resquício de autoria. Tal subterfúgio analítico reveste-se de retórica; não passa de artifício. O terreno, porém, está minado de rodapés, legendas e releituras para ser abordado de maneira unidimensional. Percorrê-lo devagar pode ser o expediente mais eficaz para compreender seus limites e fundamentos. O primeiro passo é proceder a uma desmontagem da obra, sem situá-la. O poder efetivo da análise musicológica "neutra" será assim posto em ação e testado. As disjecta membra poetae serão recolhidas no fim do segundo capítulo, com as referências históricas. $\mathrm{O}$ terceiro se ocupará da biografia do autor. A situação cultural da peça e as discussões nascidas dela estarão no quarto. Em apêndice, a partitura completa. É necessário agora ler apenas com a razão a passagem que inicia um determinado madrigal, cujo título se dá a conhecer pelo primeiro verso. Ao mencionar a forma "madrigal", já se indicam datas. Ela vicejou entre o final do século XV e o início do XVII. Por que não esquecer tais detalhes? Considere-se o trecho em si mesmo, conforme "Exemplo 1 " a seguir.

Quatro das cinco vozes apresentam uma tese em motivo homofônico carregado de dissonâncias - isso se o ouvinte estiver de acordo com as leis tonais de Jean-Philippe Rameau ${ }^{7}$. Intervalos de quarta não eram tidos

7. Jean-Philippe Rameau, Treatise on Harmony (Traité de l'Harmonie), Translation by Philip Gosset, 1722, New York, Dover Publications Inc., 1972, p. 44. 
Exemplo 1

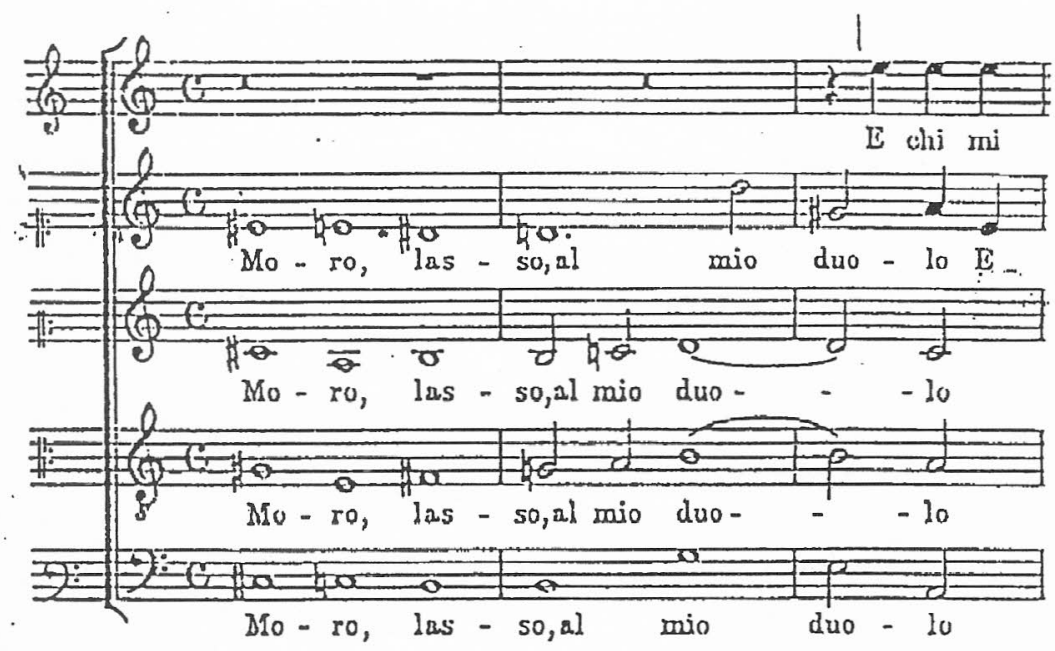

como dissonantes no momento em que a obra foi escrita, por enquanto não importa quando. Mas, ainda assim, as presumíveis dissonâncias se resolvem no fim da seqüência, num clássico percurso cadencial. A peça inicia-se com um acorde de dó sustenido maior para concluir num lá menor, em progressão de quintas, passando por lá, si maior, sol, mi com sétima. Comparecem onze dos doze semitons da escala cromática. A aparente presença de um centro tonal (lá menor) mascara uma cadência frígia incompleta (sem o si inicial). A escala cromática da segunda voz é descendente, enquanto as três mais graves desenham o percurso contrário, em discreto contraponto. O movimento é lento, grave.

Tantos acidentes diagramam o verso "Moro, lasso, al mio duolo" (Morro, pobre de mim, da minha dor) de maneira silábica. Cada acorde imprime à letra uma carga emocional que talvez ela não possuísse de início.

No trecho que segue, outro afeto engendra outra configuração agógica, melódica e harmônica. O verso heptassílabo "E chi mi può dar vita" (E quem me pode dar vida) contrasta com o anterior em sentido e em som. "Vita" ocupa o espaço de "moro"; vida de morte. As vogais claras como "i" e "a" suplantam em volume as escuras "o" e "u". A melodia sai subitamente do ambiente cromático para evoluir em diatonia. $\mathrm{O}$ episódio é dramatizado, com sequiências imitativas e notas rápidas. A 
harmonização contém o atrevimento, para fazer soarem as palavras. A linguagem cromática, baseada na conjunção e disjunção dos modos medievais, dá lugar a um tonalismo ambíguo. Mas é mais adequado ouvir antes de entrar em considerações historicistas. Suspender a descrença na sincronia proporciona uma vida estética que talvez a obra não tivesse se situada no tempo e no espaço.

\section{Exemplo 2}

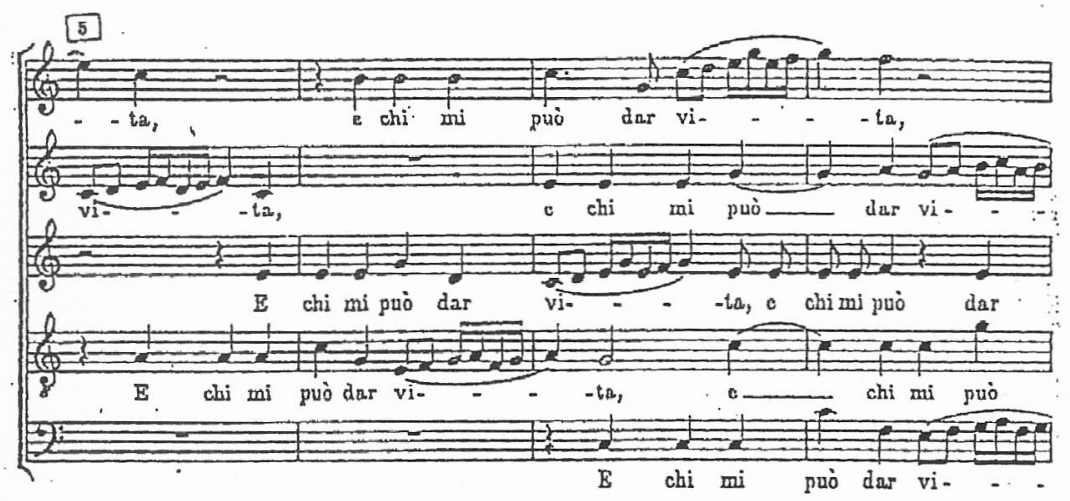

Uma terça diminuta introduz a terceira sequiência (compassos 10 a 15). Um cânon se expande lentamente e se fazem ouvir sucessões de acordes modulatórios e dissonâncias não-preparadas. Diz a letra, outra vez contrastante, agora em hendecassílabos: "Ahi, che m'ancide e non vuol darmi aita!" (ai. que me mata e não quer me dar ajuda!). Ocorre uma repetição variada dos acordes proposto anteriormente, uma exacerbação dissonante. $\mathrm{O}$ gesto hiperbólico se interrompe em uma pausa (compasso 16), conforme "Exemplo 3"a seguir.

O motivo inicial retorna, agora com os acordes alterados e transposição para as vozes agudas. A cláusula da cadência, porém, é sincopada e o novo episódio - dramático imitativo - se desenrola mais rapidamente, com tema variado. "Moro, lasso, al mio duolo/ E chi mi può dar vita" (compassos 15 a 24), os versos são reiterados enfaticamente. O trecho canônico a seguir ganha pequenas mudanças rítmicas. O quarto e penúltimo verso, "O dolorosa sorte", uma interjeição, faz o papel de abóbada nessa conturbada 
Exemplo 3

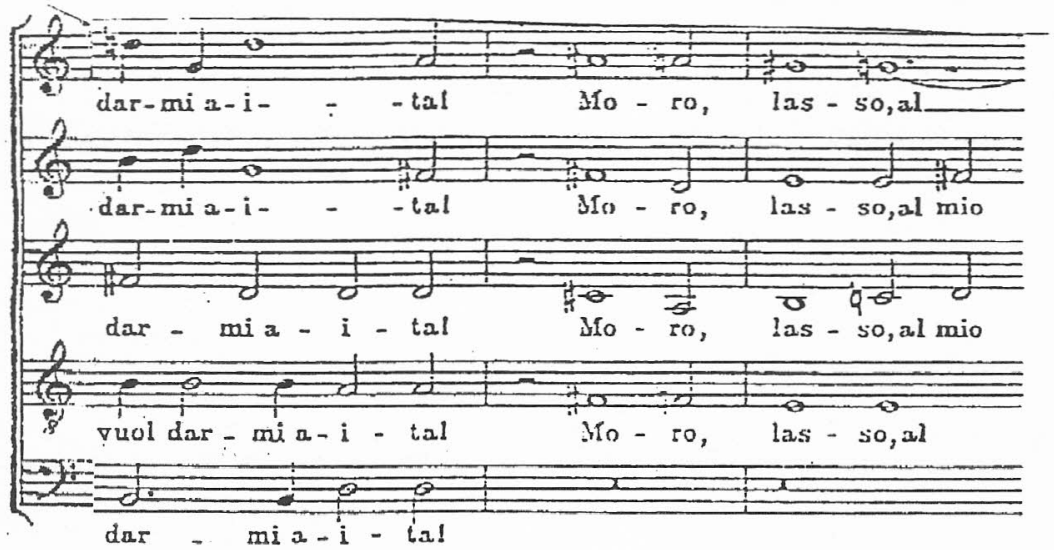

construção. Ela se erige nos compassos 30 e 31 do madrigal. Colisões de semitons, intervalos de segunda e quarta se acumulam no curto espaço de seis sílabas. Dá-se, em dois compassos, uma progressão harmônica que vai do si bemol com sétima para mi maior. Em "sorte" justapõem-se acordes distantes como de si bemol maior com sétima e mi maior. Observe-se o intervalo de segunda nas duas vozes agudas, uma no si bemol e outra no lá. Um turbo metafísico amplifica o poder da palavra "sorte", com o atributo "dolorosa" a fazer uma escada de modulações rápidas.

O decassílabo final, "Chi dar vita mi può, ahi, mi dà morte!" (Que me dar vida pode, mas ai, me dá morte!), é reiterado em passagens harmônicas e logo adiante imitativa com formato diatônico. É o recitar cantando em sua forma quase perfeita, não fossem as cinco vozes. Os três compassos finais conduzem a exclamação "ahi, mi dà morte!" para a atmosfera modal e cromática. A cadência, com dissonâncias preparadas e contraponto clássico, deixa-se concluir em um acorde perfeito de lá. Uma cláusula dramática, exasperada, conforme "Exemplo 4" e "Exemplo 5" a seguir.

\section{O Fonema Culto}

Cabe ainda retardar a referência de autor e as datas. Apesar disso e apesar de a partitura não ter sido vislumbrada em sua integridade, já se 
Exemplo 4

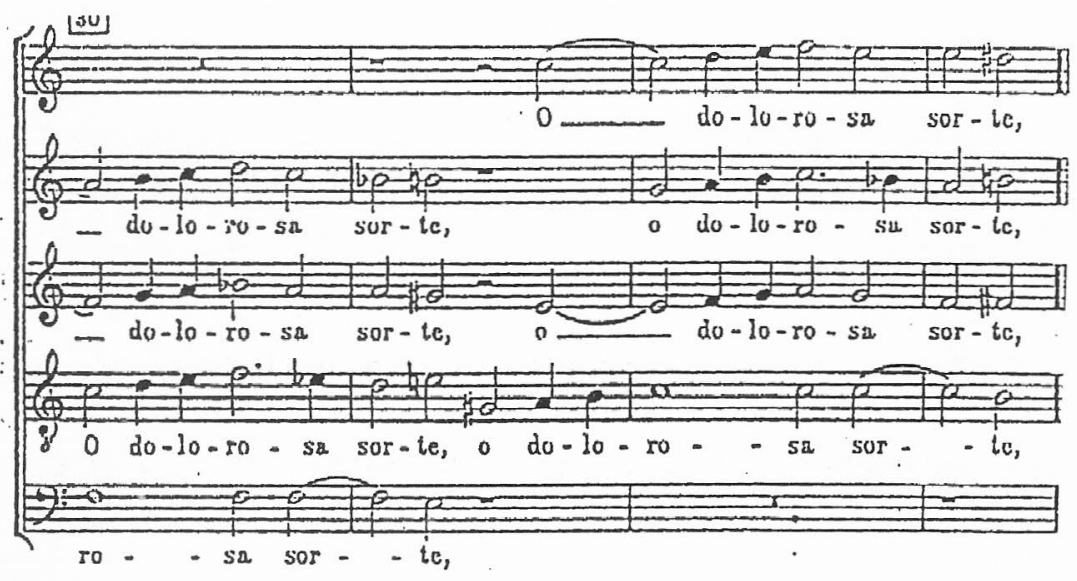

Exemplo 5

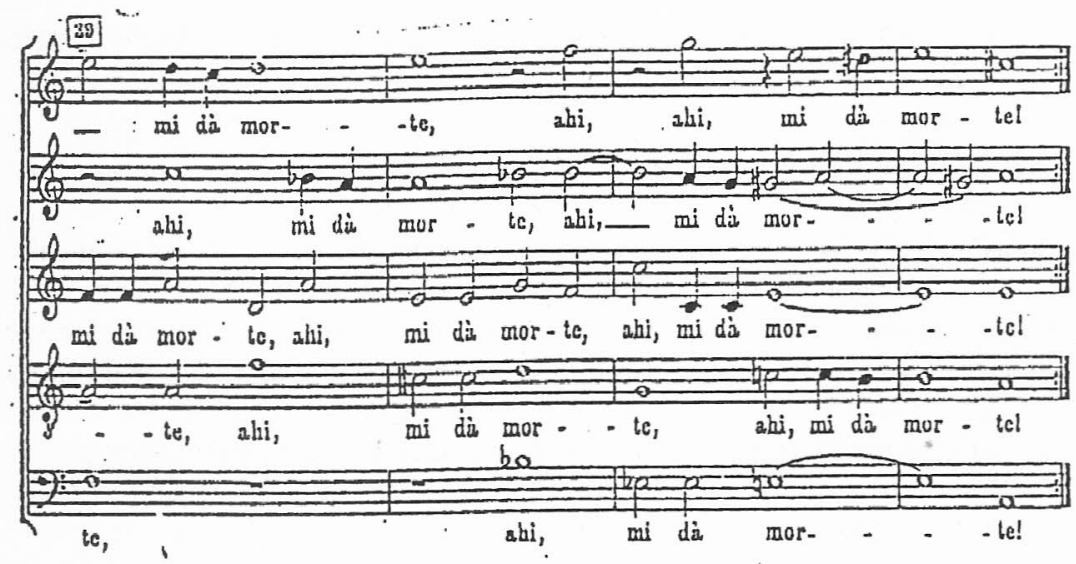

pode ter uma noção do funcionamento do madrigal. O poema fornece a forma para a composição. Basta lê-lo em sua forma genuína:

Moro, lasso, al mio duolo

E chi mi può dar vita,

Ahi, che m'ancide e non vuol darmi aita! 
O dolorosa sorte,

Chi dar vita mi può, ahi, mi dà morte! $!^{8}$

A quem pertence o poema ainda é necessário calar. Sua leitura sugere que o compositor agiu como um leitor privilegiado (e psicanalítico, de certo modo) do poema, insuflando-lhe novos sentidos. Provavelmente se trata de uma poesia per musica, um poema feito para ser musicado. De uma forma dupla, de parte do músico e do poeta, o logos recebe nova dimensão na espécie da phoné programada, do símile erudito da organização fônica natural. O poema se quer música, ao passo que a música anseia em ser leitora, tornar-se poema em última instância. Os dois registros estéticos transladam a obra para o plano abstrato da reflexão estética. Na prática, notas e sílabas põem em jogo instâncias que sempre estiveram em relação problemática. Tocam o fulcro da questão do logocentrismo na cultura ocidental.

Conforme Jacques Derrida em Gramatologia ${ }^{9}$, a essência do logocentrismo encontra-se no fonocentrismo. A voz, assim, aproxima o significado verbal do ser. O pensador francês lembra "Da Interpretação" (1,16 a 3) de Aristóteles para discorrer sobre o "liame originário" entre logos e phoné.

Tal como foi mais ou menos implicitamente determinada, a essência da phoné estaria imediatamente próxima daquilo que, no "pensamento" como logos tem relação com o "sentido"; daquilo que o produz, que o recebe, que o diz, que o "reúne". Se Aristóteles, por exemplo, considera "os sons emitidos pela voz" (ta en te phoné) são os símbolos dos estados da alma (pathemata tes psychés) e as palavras escritas símbolos das palavras emitidas pela voz [...], é porque a voz, produtora dos primeiros símbolos, tem como a alma uma relação de proximidade essencial e imediata. Produtora do primeiro significante, ela não é um mero significante entre outros. Ela significa o "estado da alma” que, por sua vez, reflete ou reflexiona as coisas por semelhança natural. Entre o ser e a alma, as coisas e as afecções (affections), haveria uma relação de tradução ou de significação natural; entre a alma e o logos, uma relação de simbolização convencional ${ }^{10}$.

8. Heinrich Poos, "Gesualdo Madrigal 'Moro Lasso al mio duolo'. Eine Studie zur formtechnik des musicalishen Manierismus", L. A. Seghizzi (org.), L'Opera profana e sacra di Carlo Gesualdo da Venosa, VIII Convegno sul canto corale promosso e organizato dalla coralle goriziana. Gorizia, Auditorum, 1967. pp. 83-104. O poema de Guarini é transcrito integralmente à p. 84.

9. Jacques Derrida, Gramatologia (De la gramatologie) 1966, Tard. Miriam Schneiderman e Renato Janine Riberito, São Paulo, Perspectiva, 1973, 386 pp.

10. Idem, nota 3, p. 13. 
Nos trechos musicais citados, a composição fantasia o verso de verbo originário, põe o logos ainda mais perto da essência metafísica, para seguir Derrida. A música atua como a maior das escravas da poesia. Um heptassílabo se engravida de harmonias, escalas, acidentes, um compasso quaternário, vozes em alturas distintas. Seu significado definitivo, no entanto, está expresso pela palavra, (logos) no recitar cantando: "Moro, lasso, al mio duolo". A "alma" emerge com a dominância da phoné. A letra escrita recebe o influxo irracional dos afetos, representados aqui por notas brancas.

$\mathrm{Na}$ busca de um fonema primordial, de um arquifonema poéticomusical, a composição revela consciência de linguagem por parte do artista. Uma intenção estética racional norteia a obra. A análise parcial demonstra que o compositor desejou realizar um exercício de arte como linguagem, ou como combinação de linguagens. Nessa obra (até aqui "misteriosa"), realiza-se a função poética, de acordo com a classificação já antiga do lingüista Roman Jakobson: "A função poética projeta o princípio de equivalência do eixo da seleção sobre o eixo de combinação. A equivalência é promovida à condição de recurso constitutivo da seqüência", argumenta o sábio russo ${ }^{11}$. Mais adiante, esclarece que todos os elementos constituintes de uma sequiência poética se igualam:

Longo (prosodicamente) iguala longo, breve iguala breve; fronteira de palavra iguala fronteira de palavra; ausência de fronteira iguala ausência de fronteira. pausa sintática iguala pausa sintática. ausência de pausa iguala ausência de pausa. As sílabas se convertem em unidades de medida, e o mesmo acontece com as moras ou acentos.

Ora, toda operação poética e toda composição musical sobre poesia trabalham com a função poética. Na composição, a função poética amplia suas valências, já que os dados musicais paradigmáticos (codificação, harmonia, melodia, ritmo, timbre, procedimentos de escritura, concepção estética) são projetados no fluxo da obra em associação simultânea ao paradigma verbal (fonemas, morfologia, sintaxe, leis de versificação etc.). A potencialização do efeito de tamanha soma é imensa. Não apenas sons se combinam a palavras naturais, mas o conhecimento da arte dos sons e

11. Roman Jakobson. (1960), "Linguiística e Poética”, Lingüística e Comunicação, trad. Izidoro Blikstein e José Paulo Paes, São Paulo, Cultrix, 1975. 8ª ed. pp. 118-162. p. 130. 
da arte das palavras se imantam reciprocamente no desenrolar de uma composição. Equiparam-se código e mensagem, lei e concretização artística da lei. O poema contém o conhecimento poético que o gerou. A composição, ciência musical. O madrigal enfeixa a metafísica, o saber e a metalinguagem numa phoné supersignificante. Ele é, portanto, o resultado complexo de diversos registros de linguagem e de axiomas.

Daí ser possível deduzir a estética que o escreveu, quando não o autor que o compôs. Ainda que não se saiba seu nome, é fácil descrever a especificidade da obra em relação a peças semelhantes. $\mathrm{O}$ que $\mathrm{O}$ madrigal mostra, sem que se pense em época? Uma estética de contrastes afetivos, em que são encenados padrões das linguagens cromática, polifônica e tonal. A harmonia é polivalente; o contraponto, dissolvido nos estados extremos, nas alterações rítmicas. Seu autor parece se aprofundar no problema da dramatização da phoné... Mas, por mais que se queira, mostra-se impossível saltar da imanência da partitura sem cair de imediato na história.

\section{Crime e Concerto}

Moro, lasso é um dos madrigais mais estudados do compositor napolitano Carlo Gesualdo, príncipe de Venosa (1560-1613). Foi escrito por volta de 1600 e publicado em 1611 no sexto livro de madrigais do compositor ${ }^{12}$. Na peça, de número XVII na coleção, o autor vale-se do poema do escritor maneirista ferrarense Giovanni Batista Guarini (15381612), um de seus favoritos, ao lado de Torquato Tasso (1544-1595). Moro, lasso pode ser abordado como o emblema da obra completa de Gesualdo, ao todo 147 composições distribứdas em seis tomos, publicados esparsamente ao longo de 17 anos, entre 1594 e 1611. O século XX tende a enxergar o legado do mestre como prefiguração do Romantismo e até precursor da politonalidade moderna, como será demonstrado mais adiante.

Na prática musical barroca e clássica, Moro, lasso, constituiu um pomo de discórdia. Serviu para justificar tanto a construção de um sistema estético (a Affektenlehre, de Athanasius Kircher) e a aparição de uma

12. Don Carlo Gesualdo, 1594-1611, Sämtlcihe werke. Ed Wilhelm Weismann e Glenn Watkins. Hamburg, 1957-1966, 10 vols. 
prática musical revolucionária (a Seconda Prattica de Claudio Monteverdi), como para tentativas de destruição da reputação artística de seu autor.

O último aspecto exige uma digressão. A personalidade de Gesualdo é tão marcada por tragédias que se torna quase impossível dissociá-la de sua música. Torna-se indispensável conhecer o homem para depois evitálo e compreender a polêmica que se sucedeu quando vivia e logo depois de sua morte.

"Il signore Prencipe", como era tratado por seus contemporâneos, não só foi um artista de frente na experimentação musical do final do século XVI e nobre riquíssimo do sul da península, como se envolveu numa trama passional que até hoje rende ficção barata. De alguma forma, o caso ajuda a explicar parte das razões que levaram o nobre a se dedicar à música.

Acompanhado por três homens armados de arcabuzes e espadas, Gesualdo assassinou a mulher, Maria D'Avalos, o amante, Fabrizio Carafa, Duque de Andria, na noite de 16 de outubro de 1590 no palácio Sansevero em Nápoles. O episódio é cantado em dezenas de narrativas galantes da época. Brantôme desce a detalhes mórbidos na coleção de crônicas Vies des Dames galantes ${ }^{13}$. A narrativa de ficção mais famosa em torno do escândalo data de 1921 e se intitula "Histoire de Doña Maria D'Avalos e du Duc D'Andria". Seu autor, Anatole France, baseia-se em Brantôme para criar um conto, que figura na coletânea Les Puits de Sainte Claire ${ }^{14}$. Mais confiáveis são Cecil Gray e Philip Heseltine na biografia Carlo Gesualdo, Musician and Murdered. O livro fornece documentação completa sobre o tema, tendo inclusive lançando mão da "Informatione preso dalla Gran Corte della Vicaria", a investigação realizada pelo governo napolitano vinte dias após o crime ${ }^{15}$. Isso não impede, porém, que a dupla de autores deixe de citar documentos de época ainda mais mórbidos, referidos no excelente ensaio "Gesualdo, The Man and His Music", de Glenn Wat-

13. Le Seigneur de Brantôme, (1614), Vies des Dames galantes, Paris, Garnier, 1925.

14. Anatole France, (1921), Histoire de doña Maria D'Avalos et du Duc D'Andria, Les Puits de Sainte Claire. Paris, Calmann-Lévy, Éditeurs, 1921, pp. 271-286.

15. Gray, Cecil e Heseltine, Philip, 1926, Carlo Gesualdo, Musician and Murdered, Westport, Greenwood Press, 1975, pp. 20-32. 
kins $^{16}$. Conforme conta um cronista da época, Spacini, citado pelo estudioso inglês, ao amanhecer do crime, Gesualdo mandou jogar os cadáveres nus e mutilados dos amantes na escadaria do palácio, para serem vistos pelo público. "Contou-se que enquanto os ditos cadáveres estavam estirados na dita escada, um monge de São Dominos, a terziario, usou a dita Donna Maria, apesar de ela estar morta", narra o cronista $^{17}$.

O remorso o levou a se refugiar no castelo de Gesualdo, vilarejo a cem quilômetros de Nápoles, posse da família havia 600 anos. Ali, contam as genealogias da nobreza italiana, o príncipe passou a se dedicar única e exclusivamente à música. Seu período criativo mais fecundo se deu entre 1593 e 1600. Na época, excursionou por Roma e o norte da Itália. Passou longos períodos na corte de Ferrara. Ali, em 1594, casou-se com Leonora d'Este, filha do marquês de Montecchio. Em Ferrara e outras cidades, o príncipe viveu para música. O musicólogo Alan Newcomb reuniu testemunhos desse período ${ }^{18}$. De sua monografia resulta um retrato muito vivo dâ melomania de Gesualdo. O compositor Emilio di Cavalieri deixou um relato sobre um encontro com o príncipe, em 19 de dezembro de 1593, em Roma: "O Príncipe de Venosa, que não gostaria de fazer nada além de cantar e tocar música, hoje me forçou a visitá-lo e me manteve lá por sete horas. Depois disso, acho que não ouvirei música por dois meses" 19 . O embaixador de Ferrara em Roma relata num despacho de 15 de dezembro daquele ano, também citado por Newcomb: "Ele parece perdido na música, já que só fala disso e não quer outra coisa além disso. Entendo que ele toca alaúde, o cravo e a guitarra e que ele é um grande compositor também" 20 .

Ainda segundo a documentação de a, encontrada em Modena, o conde Alfonso Fontanelli acompanhou Gesualdo na viagem e deixou cartaz sobre as peripécias de sua alteza. Conta que Gesualdo falava abertamente de sua arte e mostrava para todos dois tomos de partituras com

16. Glenn Watkins, 1973, Gesualdo, the man and his music. Preface by Igor Stravinsky. London, Oxford University Press, 1973.

17. Apud, Watkins, p. 13

18. Alan Newcomb, "Carlo Gesualdo and a Musical Correspondence of 1594", The Musical Quarterly, vol. LIV, n. 4, october, 1968, New York, Paul Henry Lang Editor, 1968. pp. 409-436.

19. Idem, nota 12 , p. 411.

20. Idem, ibidem. 
madrigais a cinco vozes. "Mas disse que, por ter só quatro que cantam, vê-se forçado a entrar como quinto" 21 . Fontanelli revela uma confissão do príncipe: "Disse ter deixado seu primeiro estilo e começou a exercitar na imitação do Luzzasco, por ele sumamente amado e celebrado, se bem que ele diga que não haja feito todos os seus madrigais com o mesmo estudo, como pretende mostrar a ele próprio"22. Luzzasco Luzzaschi, um dos principais compositores do estilo cromático em voga na época, era músico da corte de Ferrara, aliás terra natal de Nicola Vicentino, o fundador do estilo cromático e construtor do archicembalo (que continha dividia a escala em semitons enarmônicos). Luzzaschi se apresentava habitualmente no arquicímbalo. Gesualdo emulava e admirava Luzzaschi e Vicentino. Dedicou os primeiros madrigais àquele e quis possuir uma duplicata do archicembalo em seu castelo. Não é de duvidar que tenha conseguido e até composto com ele algumas de suas fantasias enarmônicas.

O gusto difficile de Don Carlo era anotado por Fontanelli, quando de sua visita a Veneza, em maio de 1594. Na época, ele também entrou em contato com a Camerata Bardi, de Florença. Liderada pelos compositores-teóricos Vincenzo Galilei e Giulio Caccini, discípulo de Vicentino, a Camerata desejava restabelecer as leis das escalas cromáticas e da monodia acompanhada dos gregos através de uma nova forma de arte: a ópera. Um dos alunos de Caccini, o cantor e guitarrista Francesco Rasi, trabalhou para Gesualdo entre 1596 e 1598, segundo observa Newcomb ${ }^{23}$. Don Carlo mantinha em seu castelo um grupo de músicos em constante atividade. Entre eles figura o madrigalista Pomponio Nenna, outro artífice do cromatismo e autor de madrigais inspirados em Gesualdo. Ele trabalhou em Gesualdo entre 1594 e 1599 . Há pelo menos 15 peças em que Nenna utiliza as fontes poéticas e os procedimentos musicais do príncipe. Houve, certamente, mão dupla nessa emulação musical. Gesualdo gostava de desafiar os mestres polifônicos e, apesar do contato, nunca se sentiu à vontade com o estilo monódico da Camerata. Sua reputação se estabeleceu ainda no fim do século XVI. Fez publicar seus dois primeiros livros (pelo gráfico Vittorio Baldini, Ferrara, 1594) sob o pseudônimo de Gioseppe Pilonij. Os volumes subseqüentes vieram à luz sem sua

21. Idem, p. 413.

22. Idem, ibidem. 
permissão expressa. Quarto apareceu em 1595, quinto em 1596 (sob os auspícios Hettore Gesualdo). Giovanni Pietro Capuccio publicou os quinto e sexto volumes. Foi um dos poucos compositores da época a ter edição de obras completas.

No fim da vida, isolado e afeito a acessos de depressão e cólera, compôs obras sacras. De acordo com Watkins, seus últimos 15 anos de vida se revestiram de total improdutividade. Segundo o Ferrante della Marra, em Rovine di Case Napolitane del suo Tempo (1632), citado por Watkins ${ }^{24}$, o príncipe se viu afligido nos últimos tempos por "uma horda de demônios". Para obter tranquiilidade, valia-se de 12 criados, que o batiam três vezes ao dia, "durante cuja operação ele sorria em gozo" 25. Morreu em 3 de setembro de 1613 de causa desconhecida, provavelmente de males decorrentes da asma e de complicações intestinais. Com ele, foi enterrado o madrigal. Mesmo assim, alguns compositores barrocos tentaram praticá-lo bissextamente, como Schütz, Alessandro Scarlatti e Antonio Lotti (1667-1740). Este publicou em 1705 a última coleção conhecida do gênero - inspirada no estilo do príncipe de Venosa.

\section{Versões Gesualdianas}

O sujeito Gesualdo reflete tão intensamente sua obra que o estudioso é levado a fazer considerações sobre o temperamento maníaco-depressivo do mestre e tentar, a partir daí, explicar a obra. Nada mais coerente do que uma personalidade despótica e demoníaca criar um dos exemplos mais perfeitos de individualismo na música. Afastado do mundo, Gesualdo representou em sons organizados a derrota amorosa e a morte pelo amor. Sua linguagem musical pode bem ser conceituada como o espelhamento da dissolução dos sentimentos, reordenados em estruturas dúbias e em constante erupção. Tal linha de raciocínio pseudo-psicanalítica foi evitada desde o início deste trabalho, por ser mais mitológica do que racional. Não há dúvida de que as circunstâncias biográficas do homem se apresentam na obra. A escolha do tema da depressão amorosa e da autodestruição, a insis-

23. Idem, p. 422.

24. Idem, nota 10, pp. 83-84. 
tência na dissolução das estruturas polifônicas, a obsessão na carga contrastiva da expressão, tudo isso deriva da invenção subjetiva.

Mas há um legado mais profundo. Gesualdo realiza sua arte num período em que a discussão sobre a representação dos conceitos pela música e a relação da melodia com a poesia altera as idéias arcaicas. Dá-se, então, a alteração da função da música como arte. A era barroca ensaia seus passos iniciais, com a instauração da melodia acompanhada e o baixo contínuo e a valorização da expressividade. Se não colabora na evolução da nova prática homofônica, Gesualdo forma o ponto fulcral do progresso da expressividade em música. Remotamente, sua obra é responsável por um dos primeiros capítulos da o Herior estética da música.

Sua invenção tempestuosa se fundamenta na discussão da época. Em meados do século XVI, os músicos começavam a abandonar a polifonia e o sistema modal. Conforme Enrico Fubini, da crise da polifonia surge o debate sobre como a música deve lidar com a linguagem. A questão era urgente.

O problema de uma correspondência e uma congruência maiores entre música e palavra se fazia patente na concep̧̧ão que começara a estender-se da música como instrumento capaz de "mover afetos", dentro dessa perspectiva, fazia-se imprescindível que, a cada palavra dotada de uma determinada carga semântica, correspondesse por analogia uma harmonia equivalente em música ${ }^{26}$.

A polifonia começava a ser identificada com a barbárie gótica e com a função da música como fornecer prazer aos sentidos. A refutação da polifonia vem acompanhada pela entronização das emoções em música. Essas idéias conteudísticas de ressemantização da arte dos sons são cultivadas pelos teóricos. Gioseffe Zarlino (Institutizioni Armoniche, de 1558), lança mão do terceiro livro da República de Platão para postular o primado da oração sobre a harmonia. Cita também Horácio (aliás conterrâneo de Gesualdo): Versibus exponi tragicis res comica non volt (Um tema de comédia se recusa a ser posto em versos de tragédia). Expande a associação para letra e música, afirmando que o músico deve

25. Idem, p. 83.

26. Enrico Fubini. (1976), La Estética Musical desde la Antigüedad Hasta el Siglo $X X$, trad. para o castelhano de Carlos Guillermo Péres de Aranda, Madrid, Alianza Editorial, 1988, p. 139. 
"expressar efeitos" adequadamente: harmonia áspera deve corresponder a sentimentos ásperos. Musicalmente, significa tom, sexta maior e décima terceira, síncopes de quarta, sétima ou décima primeira sobre o mesmo tom, com movimentos lentos. Os efeitos de aflição e amargura devem se representar em música por semitom, sexta e décima terceira menores, "naturalmente suaves e delicadas" 27 . Zarlino reivindica igualmente a redução dos modos a dois tons básicos, maior e menor.

Zarlino viria a ser combatido pela geração imediatamente posterior, sobretudo no seu receituário expressivo. A preocupação semântica, no entanto, permanece em textos como o de Giovanni Bardi, Galilei e Monteverdi. Bardi recorre em 1580 à República de Platão num discurso em que defende a submissão da música à poesia: "Como a alma é mais nobre que o corpo, assim também a palavra é mais nobre que o contraponto, e como o corpo deve ser pela alma regulado, o contraponto deve seguir norma das palavras" ${ }^{28}$. Um ano depois, Galilei no "Dialogo della Musica Antiga e della Moderna", texto canônico para a Camerata Florentina e para o surgimento da ópera, critica a diversità da polifonia, causadora de confusões auditivas, e propõe com tarefa principal da música "a imitação das concepções que derivam das palavras" 29. Gesualdo provavelmente leu o tratado de Galilei, já que este distingue a imitação das palavras da imitação do conteúdo geral dos conceitos trazidos pelas palavras. Gesualdo iria trabalhar justamente na representação expressiva dos conceitos pela música.

Em 1607, Monteverdi pediu ao irmão que prefaciasse seu quinto livro de madrigais. Mais uma vez, citou-se a República para apoiar a defesa da poesia e a simplificação da harmonia. "Quando a harmonia é serva das palavras, a maneira de empregar as consonâncias e dissonâncias

27. Gioseffe Zarlino. (1558), "Instituzioni armoniche", em Oliver Strunk (org. and transl.). Source Reading in Music History, $2^{\mathrm{a}}$ ed., New York, London, W. W. Norton \& Company, 1965, vol. 2, The Renaissance, pp. 38-72, p. 69.

28. Giovanni Bardi. (1580), em "Discorso mandato a Giulio Caccinni detto romano sopra la musica antica, e "I cantar bene", em Claude V. Palisca, The Florentine Camerata (Documentary Studies and Translations), New Haven, London, Yale University Press, 1989, pp. 132-151.

29. Vincenzo Galilei, 1581, "Dialogo della Musica Antica e della Moderna", em Oliver Strunk (org. and transl.), Source Reading in Music History, 2. ed., New York, London, W. W. Norton \& Companye, 1965, vol. 2, pp. 112-132. 
não é determinada de um modo estabelecido, porque uma harmonia difere de outra nesse respeito. De certa maneira, a harmonia prepara intrinsecamente e dispõe para alegria ou tristeza, mas não leva por esse motivo à expressão de nenhum efeito extrínseco" 30 . Monteverdi chama a Seconda Prattica de "a melodia como perfeição da música"31. "A harmonia é sempre igual, tendo chegado ao seu limite, e portanto é incapaz de obedecer as palavras perfeitamente". Assim, trabalha na segunda prática aquele que "considera harmonia não comandando, mas comandada, e faz da palavra a senhora da harmonia" ${ }^{32}$. Cita, entre outros "fidalgos dessa heróica escola", "il signor Prencipe di Venosa"33.

A harmonia surge com o melodrama, comenta Fubini. Gesualdo trabalha no centro das transformações, ou, como diz Manfred Bukofzer, no "giro decisivo da harmonia de intervalos para a de acordes, da dissonância preparada à não preparada" 34 . A nova dimensão espetacular da música encontra no príncipe de Venosa o palco abstrato no qual atuam sentimentos contraditórios. Gesualdo reelabora a nascente estética musical na prática. Tenta responder ao desafio metabolizando as três linguagens que se engalfinhavam: a polifonia modal, o cromatismo e a incipiente homofonia tonal. Segundo um estudo clássico de Edward S. Lowisnky ${ }^{35}$, a crise da modalidade no fim do século XVI se compara à da atonalidade no século XX. Elas obrigam à formulação de novos princípios organizacionais. Segundo Lowinsky, Gesualdo vai dar conta do "novo mundo de sons" ao elaborar aquilo que ele entende por "atonalidade triádica", ou seja, o cromatismo extremo e a modulação incessante se passam em uma textura de harmonia triádica, sem, no entanto, um centro tonal está$v^{2} l^{36}$. 'Em vez do grande número possível de harmonias triádicas basea-

30. Claudio Monteverdi. (1607). "Forword to Il quinto libro de'madrigali, with the 'Declaration of his brother GF. Monteverdi', em Oliver Strunk (org. and transl.), Source Reading in Music History, 2. ed., New York, London, W. W. Norton \& Company, 1965, p. 49.

31. Idem, ibidem.

32. Idem, ibidem.

33. Idem, p. 50.

34. Manfred Bukofzer (1947), La Música en la Época Barroca, de Monteverdi a Bach (Music in the Baroque Era - from Monteverdi to Bach), trad. Clara Jnés e José Triana, Madrid, Alianza Editorial, 1986, p. 50.

35. Edward S. Lowisnky, 1961. Tonalsty and Atonality, em Sixtenty-Century Music, Berveley University Press, 1961. rev. 1962.

36. Idem, p. 39. 
das na raiz, Gesualdo privilegia harmonias abertas de acordes de sexta e quarta, acordes diminutos e aumentados, dissonâncias agressivas, agudas relações entrecruzadas e acordes de quatro tons" 37 . E arremata numa comparação que se banalizou: "E, nenhuma outra música antes de 'Tristão' amor e morte foi levado a produzir um arte com visão tão poderosa e uma intensidade tão mórbida" 38 .

O reconhecimento teve longa posteridade. Gianbattista Doni, no Trattato de'Generi, de 1635, apelida Gesualdo de "o verdadeiro príncipe dos músicos" 39 . Para ele, o músico exerceu influência definitiva no cantare affetuoso da ópera seiscentista, com suas harmonias ásperas e canto embargado. O alvo de Gesualdo, segundo Doni, foi a commotione degl'affetti e não simplesmente il diletto o deleite. Ele criou um polifonia que expressa os movimentos da alma, objetivo da nova monodia.

A célebre Affektenlehre, teoria dos afetos, forjada pelo sábio alemão Athanasius Kircher na Musurgia Universalis sive ars magna consoni et dissoni (1650) demonstra que o príncipe é reconhecido universalmente como tendo sido o primeiro a ter conduzido a música ao presente estado de excelência: "Num certo madrigal seu, que começa com Baci soavi, e cari, ele expressa de tal maneira o afeto amoroso, seguindo o exemplo da natureza que nada mais poderia ser desejado" 40 . Kircher cataloga de Paradigma affectus gaudiosi os melismas que Gesualdo usa na palavra gioia (alegria) ${ }^{41}$.

A "polemica Gesualdo", travada pelos iluministas, polarizava-se entre a subestimação do diletante, amado pelas damas (Rousseau em sua enciclopédia) e a pecha do licencioso harmonizador (Burney ). Este em sua A General History of Music (1776-1789), dispende muita tinta para refutar o compositor napolitano ${ }^{42}$. A bête noire predileta de Burney é justamente Moro, lasso. Interessado em retrucar à admiração de seu colega, Sir John Hawkins (A General History of the Science and Practice of Music, 1776), Burney afirma:

37. Idem, p. 43.

38. Idem, ibidem.

39. Apud Gray \& Heseltine, p. 89.

40. Apud Watkins, pp. 300-301

41. Nino Pirrotta (1961), "Gesualdo", em Stanley Sadie (org.), The New Grove Dictionary of Music and Musicians, London, MacMillan Publishers, 1980, p. 317.

42. Charles Burney, A General History of Music, London, 1776-1789. 
(Moro, lasso) é apresentado ao leitor musical como um espécime do seu estilo, e a modulação é áspera, cru, e licenciosa; na qual, começando a composição em lá menor com um acorde de dó sustenido, com uma terça aumentada, não é nem consonante com as presente leis de modulação, nem às dos tons eclesiásticos. ao qual os compositores do tempo de Venosa aderiram, já que as claves não eram estabelecidas e determinadas no princípio fixado da maior e da menor. Mas uma licença ainda mais ofensiva é tomada no segundo acorde desse madrigal, mais do que do primeiro. pois não é só repugnante a qualquer regra de transição presentemente estabelecida, mas extremamente chocante e desagradável ao ouvido, ir de um acorde a outro sem relação um com outro, real ou imaginária; e que é composto de sons complemente esquisitos e estranhos a qualquer clave a qual o primeiro acorde pertence ${ }^{43}$.

\section{Séculos de Sombras}

O flagelo ilusionista não durou muito, antes colaborou para que a música de Gesualdo continuasse sendo consumida até o fim do século XVIII, fato único, já que na época até Bach era considerado velho. Se o Romantismo Y. S. Bach ensurdeceu diante de Don Carlo, seu legado usufrui da estima do século XX. O musicólogo alemão Heinrich Poos exemplifica a profundidade das análises "neutras" feitas neste século de, outra vez, Moro, lasso. Apóia-se em estudos realizados por músicos do Barroco, como Federico Zuccari - L'Idea de'Pittori, Scultori e Architetti (1607) - e os estudos hireoglíficios de Marsilio Ficino ${ }^{44}$. Apresenta a obra como exemplo máximo da dialética do chiaroscuro e do expressionismo característicos do Maneirismo. "O madrigal é completamente formatado em todos os detalhes para assim dar conta da representação de todos os afetos", diz $\operatorname{Poos}^{45}$. Seu aspecto fantastico-artificiale (Zuccari) se identifica com uma estética da discordia concors. Poos corrobora o argumento de Zuccari, para o qual as deformações do contraponto do madrigal trazem à tona o concetto gesualdiano, isto é, a elaboração de "expressões dos conceitos do ânimo" (espressione dei concetti dell'animo) por meio do disegno metaforico por opostos contrários. Já Ficino encontra na figura serpentinata dos cânones das vozes agudas do madrigal uma cifra da coincidentia oppositorum dos con-

43. Apud Watkins, pp. 302-304.

44. Idem, nota 2 .

45. Idem, p. 101. 
ceitos e padrões musicais ${ }^{46}$. Para Poos, Gesualdo escreve a obra como um caleidoscópio de exposições, variantes e codas a se disseminarem 27 vezes ao longo de 70 compassos. Poos recorta a obra em três grandes blocos: a tese geral (compassos 1 a 22), a reprise variada e antitética (23 a 44) e a coda ( 45 a 70), que realiza a síntese. "No madrigal maneirista de Gesualdo a concinnitas, o espiritualismo místico e a representação naturalista dos afetos assumem um aspecto de forma musical acabada" ${ }^{47}$.

Para Alfred Einstein em The Italian Madrigal, a definição mais precisa para Gesualdo é "músico do oxímoro" 48 . Igor Stravinsky foi propagandista ainda maior de Gesualdo no século XX. Completou um madrigal a seis vozes, deixado incompleto pelo autor, orquestrou o madrigal Beltà, poi che t'assenti (Monumentum pro Gesualdo, 1960) e chamou a atenção para a questão da interpretação das obras do compositor. "As referências de Mazzochi sobre Gesualdo levam a inferir que ele pode ter usado crescendo e outras formas dinâmicas (sfumato). Os motivo dessa ilação é que Mazzochi inventou um sistema de notação de dinâmica, que agradou Gesualdo por sua exatidão" 49 .

\section{Cláusula}

Mais uma vez, retornar à partitura de Moro, lasso. Gesualdo faz a composição musical, funcionar como máquina de estados emocionais, como se a letra corresse numa linha racional e a música lhe devolvesse um registro intuitivo. $\mathrm{O}$ animismo essencial produzido pela phoné. $\mathrm{O}$ compositor faz a música realizar um trabalho de leitura, leitura exacerbada, em que as conturbações internas da estrutura da música parecem ser mais radicais do que o impulso artístico que deseja formular a um método de expressão musical do conteúdo da poesia. Uma leitura desde um sistema em revolução interna. Não se trata apenas de jogo modulatório de timbres. Concretiza a prática dos afetos, material que viria a servir como base para a Affektenlehre.

46. Idem, p. 98.

47. Idem, p. 101.

48. Alfred Einstein, The Italian Madrigal, Princenton, Princenton University Press, 1949, 3 vols., p. 709.

49. Idem, nota 10 , p. IX. 
Gesualdo monta na varredura dos estados emocionais da poesia o primeiro laboratório da ópera barroca. Sua invenção calha às inquietações finisseculares, à ambigüidade dos sentimentos, à dissipação dos valores, ao anseio pela variação eterna e a reiteração mórbida das palavras "morte" e "vida". Gesualdo encena a presença da alma (pneuma) no sopro desesperado da voz. Nele, a música se escraviza à metafísica. Ouvi-lá é pensá-la. 


\section{Anexo: Moro, lasso}

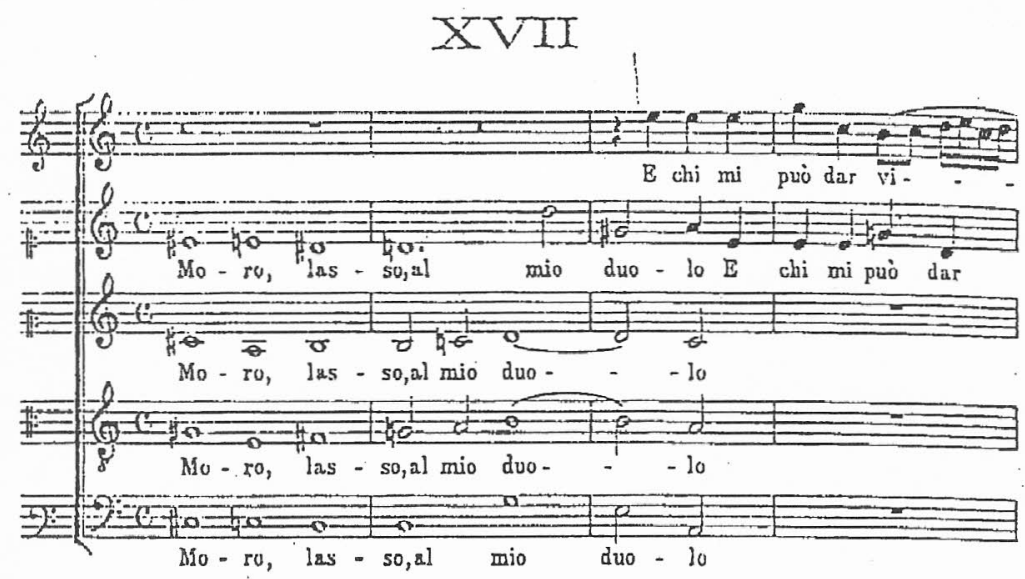

5
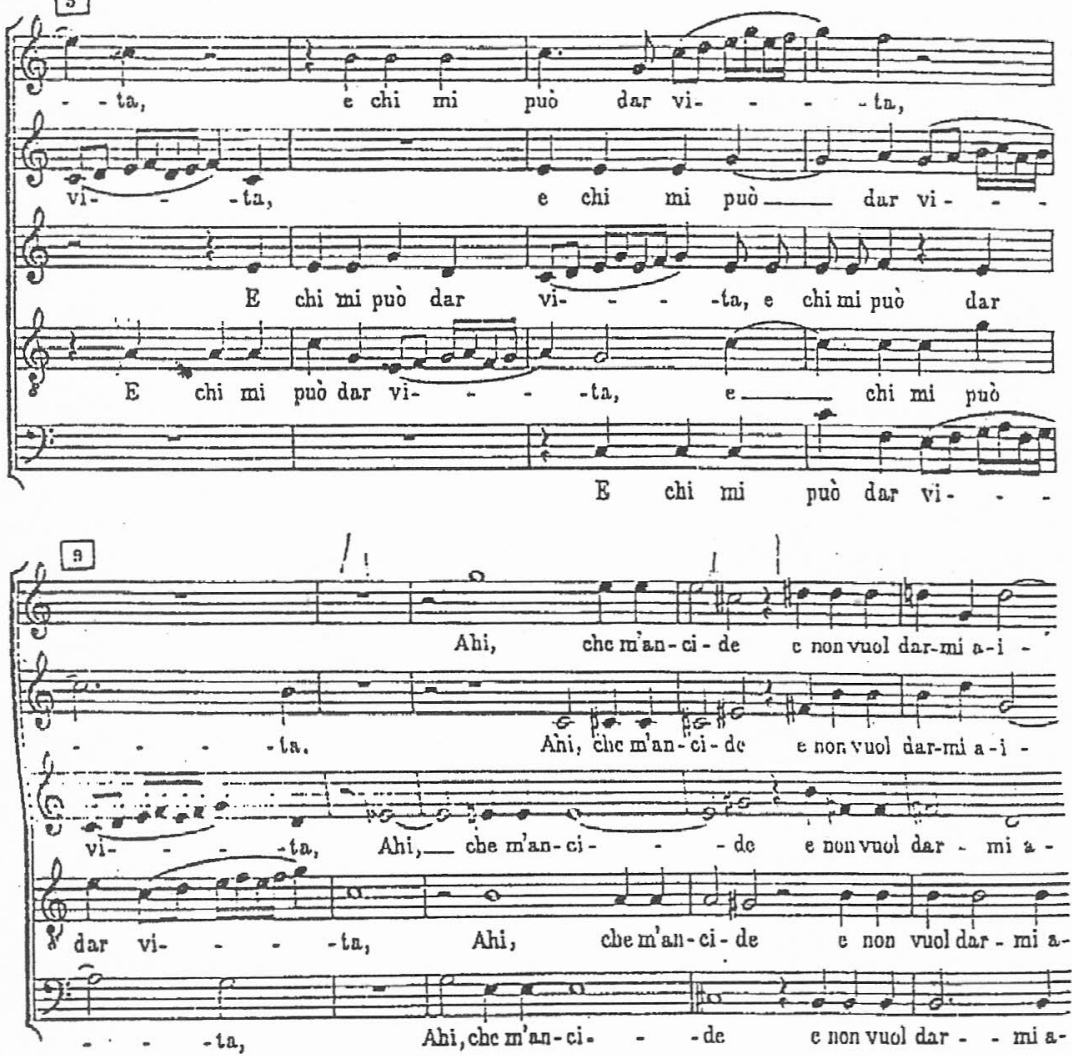


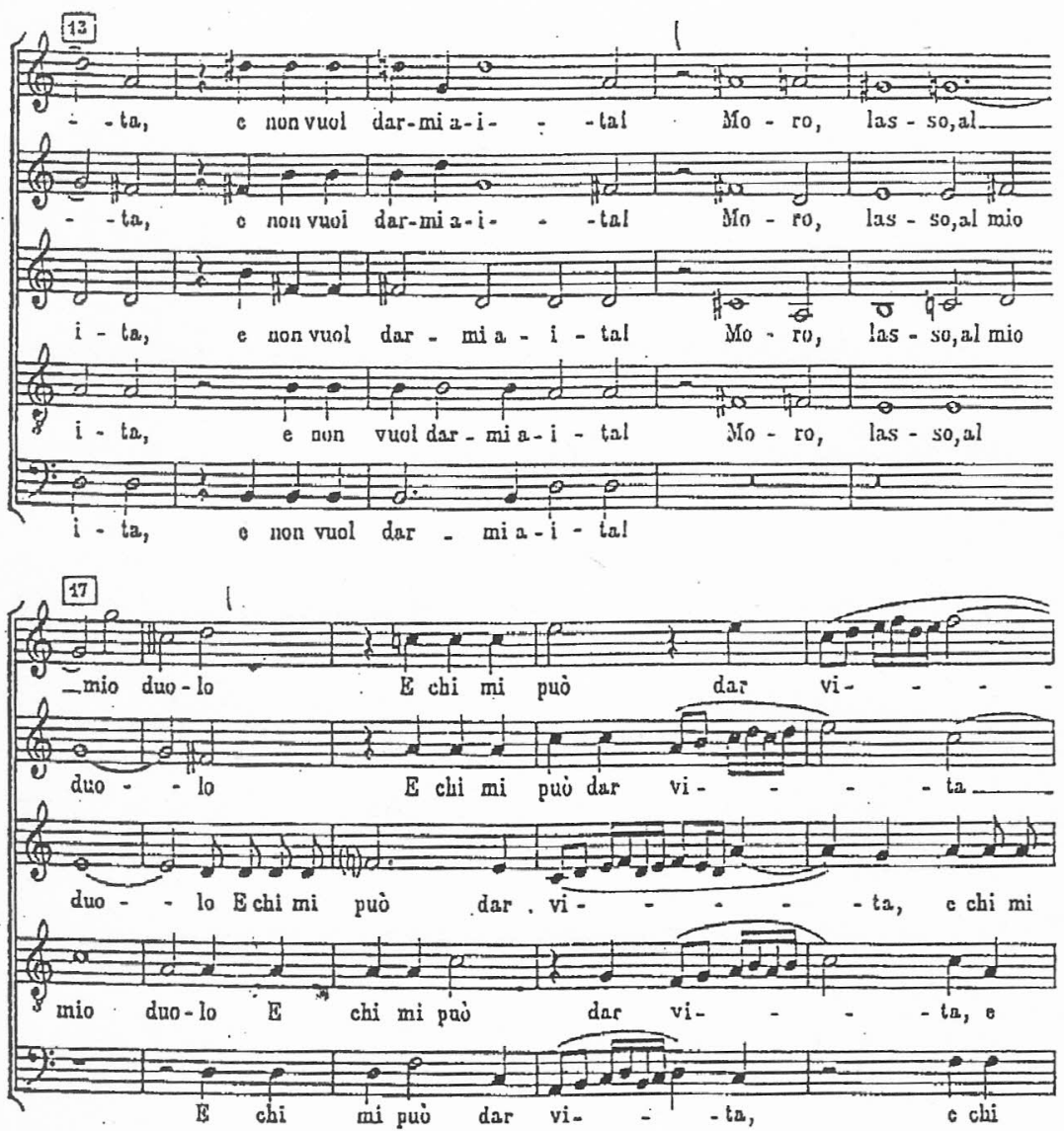

22

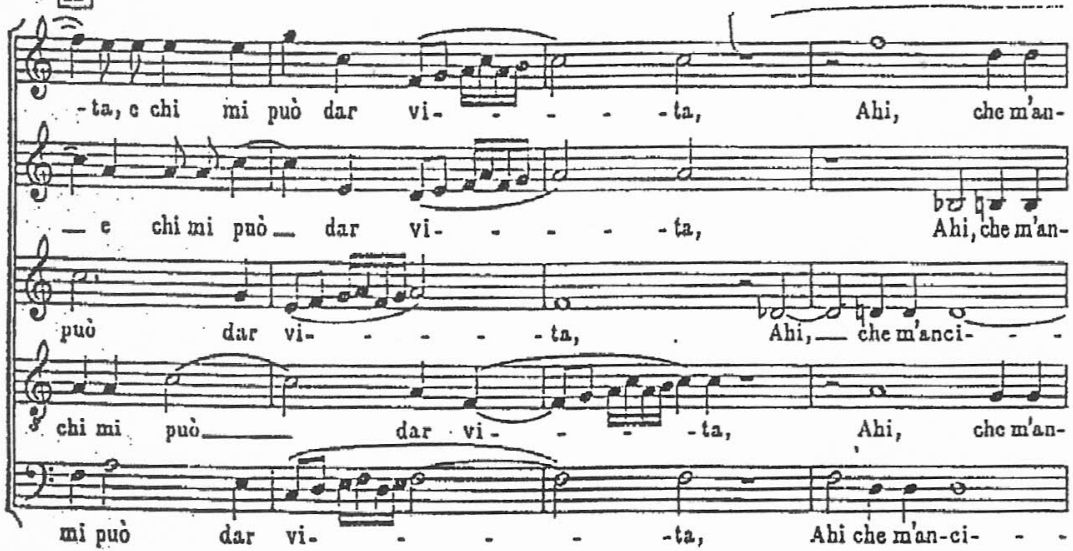



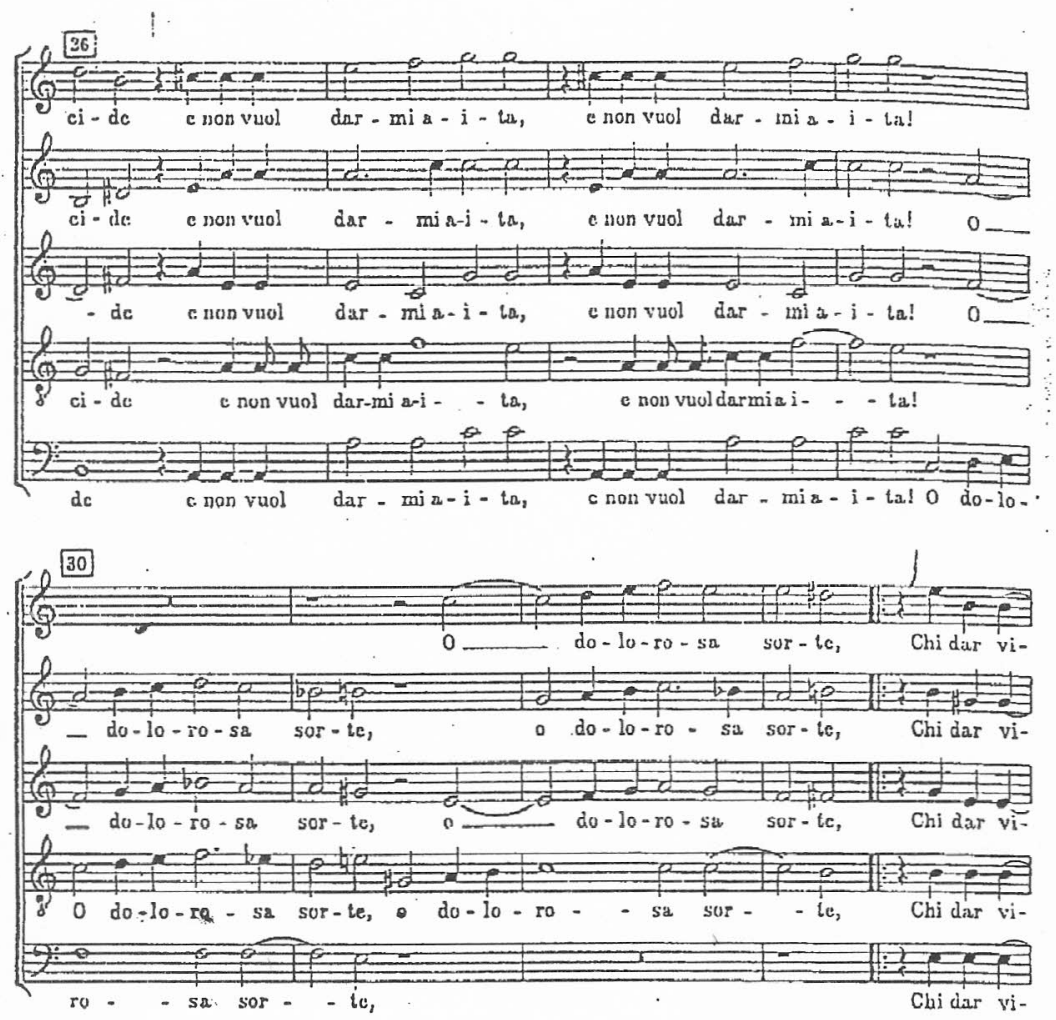